\title{
PROTECTION OF THE RADIATION WORKER*
}

\author{
By Dr. G. W. C. Kaye, O.B.E., F.R.S. \\ National Physical Laboratory
}

$\mathrm{T}$ $\mathrm{HE}$ basic ideas of protection for radiation workers by the use of remoteness and absorptive shielding are obvious enough: the remarkable thing is the time it took to secure their observance. Naturally, the X-ray tube as evolved by Röntgen and his contemporaries in 1895 onwards was entirely unprotected, but although the explanation was not clear, the dangers of superficial injuries through indiscriminate exposure to the rays had become evident within a few months of their discovery. There were those who attributed the injuries to personal idiosyncrasy, electrical effects, ultra-violet rays, platinum particles from the X-ray tubes, platinocyanides from the fluorescent screens, etc. Among other things, red silk and thin rubber sheet were actually advocated as preventives! Röntgen himself probably escaped hurt for the reason that he conducted his experiments, which were mainly photographic, with the X-ray tubes inside a metal box.

In 1898 , a committee appointed by the Röntgen Society collected evidence, much of it confusing, on the harmful effects of the rays. Presently, the principle of absorptive shielding began to emerge, and a distinction was drawn between the effects of 'hard' and 'soft' X-rays. But developments were slow, and so it happened that for many years, protection for most workers continued to be rudimentary or nearly non-existent and, whether owing to apathy or ignorance, injuries and deaths continued to result. The position was aggravated during the War of 1914-18, for many of the X-ray diagnostic sets on which the British army depended were of relatively primitive design. Such outfits, which wholly employed induction coils and gas tubes, were necessarily of restricted output, and exposures, particularly in screen examinations, were often formidable.

\section{BRITISH RECOMMENDATIONS}

A series of casualties to a number of prominent $\mathrm{X}$-ray workers during the next few years definitely aroused public opinion. It had become apparent that in addition to general deterioration of health, the signal effects were of three main types: (a) injuries to the superficial tissues (usually of

* Substance of the fourth Stanley Melville Memorial Lecture delivered before the Society of Radiographers on February 10. the hands) which, with neglect, might become ulcerated or even cancerous; $(b)$ prejudicial changes in the blood which might progress to fatal anæmia ; and $(c)$ derangements of internal organs. More effective protection for the X-ray worker was clearly necessary; but no less important to the $\mathrm{X}$-ray worker was the absolute safeguarding of the patient against accidental over-exposure, particularly in screening and therapy. In 1921 the British $\mathrm{X}$-ray and Radium Protection Committee was formed under the chairmanship of Sir Humphry Rolleston, the members being nominated by various radiological and scientific bodies. It speedily got out a series of protective recommendations which, incidentally, were the first of the kind to be issued by any country, so giving a lead to the world in these matters. These recommendations took cognizance of three primary dangers : $(a)$ undue exposure to radiation; $(b)$ high-voltage risks from exposed conductors; $(c)$ undue exposure to toxic gases produced by coronal discharge. Since 1921, the Committee has revised the recommendations on a number of occasions. In the light of greater knowledge and experience, the recommendations gained in precision and detail, and presently extended their scope to include film storage, electromedical apparatus and ultra-violet therapy.

The attention of the younger workers may be directed to the difficulties with which the British Committee was confronted in its first efforts to specify and standardize protective measures. The need was great, for the conditions in the majority of X-ray departments were thoroughly unsatisfactory in those days. The Committee realized the pitfalls of a biological unit of dosage, but a bigger obstacle was the absence of an accepted physical unit of quantity of radiation. Only a few workers had attempted to make or utilize physical measurements which could be looked upon as significant or trustworthy ; and the best the Committee could do was to try to translate into specific recommendations a sort of grand average of the protective measures which could be gleaned from the working conditions of a number of experienced radiologists who had escaped injury and still enjoyed normal health. A committee which attempts to put forward safety recommendations must err, if it errs at all, on the side of caution, and it was perhaps not surprising that at the first onset the recommendations were regarded by 
some as unnecessarily drastic, and that the embryonic efforts of the British industry, which backed the Committee's work loyally and wholeheartedly, to provide adequate protection against stray radiation, was deprecated in some quarters as heavy, clumsy and costly, and too cramping for the work of the radiologist. But presently the heavy lead-protected boxes and the like departed in favour of the self-protected X-ray tube in which the full degree of lead protection laid down by the Committee was incorporated in the tube itself, and so made it possible with lighter weight and better mechanical designs to restore the freedom of action to which the radiologist was accustomed.

Looking backward, it is scarcely possible to over-estimate the progressively beneficial influence of the Committee's recommendations on the wellbeing of the radiation worker, whether in hospitals or industrial and research establishments, as well as on the development and design of X-ray equipment. The Ministry of Health and the Ministry of Pensions gave the recommendations their support, and the National Physical Labora. tory collaborated by inspecting some hundreds of hospitals and equipment from the point of view of the recommendations. Furthermore, thanks chiefly to the activities of an Inter-Services Advisory X-ray Committee, which has functioned since 1926, the three British defence services entered the present war with X-ray departments and equipment of which the general standards of safety conform to the Protection Committee's requirements as fully as those of civilian hospitals,

\section{INTERNATIONAL RECOMMENDATIONS}

In 1928, at the second International Congress of Radiology at Stockholm, the British Committee submitted proposals based on the British recommendations as a basis for international agreement, the outcome being that they were adopted as international recommendations. An International Protection Commission was also formed with representatives from Great Britain, United States; France, Germany, Italy and Sweden, Dr. Melville and Dr. Kaye being elected secretaries. These recommendations have been revised triennially by the Protection Commission on the occasions of the successive international congresses held in Paris, Zurich and Chicago, and would no doubt have come up again in Berlin this year under happier conditions. Meanwhile, the international recommendations have been adopted in principle throughout virtually the civilized world. They have been implemented by more detailed national recommendations drawn up by protection or safety committees in a number of countries.

\section{$\mathrm{X} \cdot \mathrm{RAy}$ PRotection}

From the first, the British recommendations stressed the obvious value to both operator and patient of enveloping an X-ray tube as completely as may be with protective material of a thickness adequate for the X-ray voltage concerned. Such thickness is almost invariably stated in terms of lead, since this is the most effective and convenient absorbent readily available at a reasonable cost. The recommended thicknesses gained in precision as two major steps in progress came about. The first step was the adoption at the Stockholm International Congress of the international röntgen as the unit of quantity of $X$-radiation, based on an air-ionization method of measurement under specified conditions. The second step was the adoption by the International Protection Commission of a maximum 'tolerance dose' of X-rays. While there are a number of uncertain variables which do not lie within the province of physics but are wholly biological, the erythema dose is commonly accepted on broad grounds as an index of biological response for the average individual, the tolerance dose being taken as 1/1,000 of an erythema dose in three working days, under conditions when the whole body is irradiated. Estim. ates of the X-ray erythema dose depend on the exciting voltage, but, on the average, evaluate it as equivalent to about 600 röntgens (r.), so that the tolerance dose corresponds to 0.2 röntgen in a normal working day of 7 or 8 hours, or 1 röntgen per working week of 5 days, or $10^{-5}$ röntgen per second. The protective lead thicknesses for primary X-ray beams which are given up to $600 \mathrm{kv}$. in the latest International and British recommendations are in general harmony with this tolerance figure under average conditions, corresponding in actual fact to an initial dosage rate of about 2 röntgens per minute at the point to be shielded.

When an X-ray equipment is tested, stray radiation may be evaluated either by a convenient form of dose meter or a Geiger counter, or by carrying on the person a portable ionization chamber of small capacity, or a photographic film. In point of fact, such a film test is very sensitive, blackening which is 'just clearly visible' corresponding (with standard development) to about $0.01-$ 0.02 röntgen (that is, about $1 / 20-1 / 10$ of the daily tolerance dose), in the case of $\mathrm{X}$-rays of qualities associated with, say, 100-200 kv. The corresponding figure for gamma-rays is about 0.1 röntgen (that is, about one half of the daily tolerance dose).

As regards the protection for X-rays from higher voltages, $\mathrm{Mr}$. W. Binks and I have recently shown, on the basis of theoretical and practical data relating to photo-electric, scattering and nuclear 


\begin{tabular}{|c|c|c|}
\hline \multirow{2}{*}{$\begin{array}{c}\text { Exciting voltage } \\
\text { (pulsating) }\end{array}$} & \multicolumn{2}{|c|}{$\begin{array}{l}\text { Total lead protection required to give } \\
\text { the tolerance dosage rate of } 10^{-6} \text { r./sec. at } \\
1 \text { metre distance with } 1 \text { milliamp. tube } \\
\text { current (X-rays emitted perpendicular to } \\
\text { electron beam) }\end{array}$} \\
\hline & $\begin{array}{c}\text { Calculated } \\
\text { values } \\
\text { (Kaye and } \\
\text { Binks) }\end{array}$ & $\begin{array}{l}\text { Experimental } \\
\text { measurements } \\
\text { (Bouwers and } \\
\text { van der Tuuk) }\end{array}$ \\
\hline $\begin{array}{l}400 \mathrm{kv} . \\
600 \\
800 \\
1000 \\
2000 \\
5000\end{array}$ & $\begin{array}{l}18 \mathrm{~mm} . \text { lead } \\
40 \\
60 \\
80 \\
175 \\
290\end{array}$ & $\begin{array}{l}17 \mathrm{~mm} . \text { lead } \\
36 \\
57 \\
79 \\
=\end{array}$ \\
\hline
\end{tabular}

absorption processes, that it is possible to forecast the appropriate protective lead shielding for any voltage. We have somewhat prophetically extended our calculations up to $5,000 \mathrm{kv}$., though, in practice, $2,000 \mathrm{kv}$. is roughly the highest voltage at which $\mathrm{X}$-rays have so far been generated. The validity of the calculations, at any rate up to $1,000 \mathrm{kv}$., is supported by the good agreement with some experimental results since published by Bouwers and van der Tuuk. This is shown in the accompanying table, where it will be noted that the lead protection required for 1 million-volt $\mathrm{X}$-rays is about 3 inches, for 2 million-volt rays 7 inches, and for 5 million-volt rays nearly a foot.

Incidentally, if we may, not unfairly, regard the $\mathrm{X}$-radiation from a 2-million volt tube as comparable in quality with gamma-rays, then at 1 metre distance from such a tube operating at constant potential, the maximum X-ray output, which is of the order of 210 röntgens per minute, corresponds to the gamma-ray emission at a like distance from 16,000 grams of radium, a figure the magnitude of which may be contrasted with the total of 1,000 grams known to be isolated in the world.

\section{RAdIUM PROTECTION}

The problems which present themselves in protecting radium workers are more acute and troublesome than with X-rays. A knowledge of the radium contents of radium sources is naturally of service in this connexion. Such measurements were first put on a satisfactory footing when, following the formation at Brussels in 1910 of an International Radium Standards Committee with the late Lord Rutherford as chairman, an International Radium Standard was set up in Paris in 1913, thanks to the skill of the late Mme. Curie and the generosity of the late Sir George Beilby. In the same year, the latter also presented to the National Physical Laboratory the British National Radium Standard, which had been calibrated in terms of the International Standard, and which has since formed the basis of test of nearly 200 grams of radium.

Protection from alpha- and beta-radiations (which are virtually all absorbed in the skin) is fairly readily achieved in the case of most forms of radium manipulation. As regards gamma-radiation, the position is less satisfactory than with X-rays. Progress came when the Fifth International Congress of Radiology in 1937 accepted the röntgen as a unit for measuring gamma-rays as well as X-rays. Furthermore, the International and British Protection Committees were led tentatively to assume, on the evidence available, that the human body is equally susceptible to $\mathrm{X}$-rays and gamma-rays, and adopted the same tolerance dose for both radiations, namely, an average dose over the whole body of l röntgen per working week. There is, however, some divergence of opinion on this point, certain workers maintaining that the tolerance dose should be smaller for gamma-rays.

It should be noted that X-ray protective lead values do not apply to gamma-rays, materials lighter than lead being normally more effective against gamma-rays than X-rays. The protective thicknesses for gamma-rays may be estimated sufficiently accurately by assuming that the absorption is proportional to the density. Thus, the introduction of tungsten alloys, with a density half as much again as that of lead, has resulted in smaller and more compact radium 'bombs' without sacrifice of protection. Incidentally, the 'safe working distances' for radium bombs, calculated from the tolerance dose, are less than is often imagined; for example, the safe distance for 1 gram of completely unprotected radium is no more than 5 yards, which is reduced to 1 yard or so by enclosure in a lead bomb with $5 \mathrm{~cm}$. walls. By the same token, there is no necessity, apart from questions of air raids, to locate properly designed and protected radium safes at extravagantly large distances from the personnel.

\section{Electrical Precautions}

The practice in the pioneer days of Geissler discharge tubes, of using thin copper wire, unprotected except by silk or cotton covering, to connect the high-tension poles of induction coils or electrical machines to the terminals of discharge tubes, was a legacy which persisted with gas X-ray tubes for many years, for although an unexpected electric shock for the personnel was definitely unpleasant, nothing more serious was likely to follow. Many will recall the slack or dangling high-tension leads which carried, usually in the dark, currents at many thousands of volts, sometimes only a matter of inches from the patient or attendant. Heavier high-tension leads followed in due course, but with the advent of larger coils, and particularly of high-tension transformers, with or without condensers, the power developed was such 
that greater caution was necessary, and, indeed, fatal accidents began to occur.

The present-day solutions for shock-proofing X-ray outfits take two major forms. One is the shock-proof X-ray tube combined with hightension cable which, provided with heavy rubber insulation and earthed metallic sheathing, is both shock-proof and sufficiently flexible not to restrict mobility unduly. The other is the complete enclosing of X-ray tube and high-tension transformer in a common earthed metal container filled with a dielectric such as transformer oil or, more recently, 'freon'.

\section{Ventilation AND Lighting}

Nowadays there are no two opinions about the Protection Committee's advocacy of light schemes of decoration for all rooms (including photographic dark rooms), together with large windows affording good natural lighting and admitting sunshine and fresh air whenever the rooms are not in use. A bigger step was the introduction of artificial ventilation into $\mathrm{X}$-ray departments. The importance to the operator of generous ventilation is now recognized as second only to that of protection, particularly where apparatus is not corona-free, or the control room is not completely isolated from the treatment room. In some countries, notably the United States, elaborate schemes of air-conditioning are employed.

Mention should here be made of the importance of directional ventilation in preventing the inhaling of radioactive dust or radon during the prolonged manipulation of unsealed radium salt, radium ore, etc. ; cases of radium poisoning have occurred for lack of such precautions.

Finally, this is perhaps the most convenient place to make passing reference to the manner in which the problem of fires associated with film storage was solved by the introduction of noninflammable cellulose acetate film, in place of the highly inflammable nitrate film.

\section{Neutron Protection}

The problem of protection for the worker with neutrons seems likely to have a wider interest before long, in view of the invention of the cyclotron by Lawrence and the immense yield of neutrons which can be so obtained. It would appear from recent researches that neutrons can be measured directly in röntgens with reasonable accuracy, and that the biological activity of neutrons may be up to eighty times that of $\mathrm{X}$ - or gamma-rays, being probably dependent on the cell structure. In the interests of safety, therefore, it seems well to assume at present that the tolerance dosage rate for neutrons is of the order of $1 / 100$ of that for $\mathrm{X}$ - and gamma-rays, that is, about $10^{-7} \mathrm{r}$. $/ \mathrm{sec}$.

As regards the protection of personnel against neutrons, the task would be the easier if human tissue were not so effective in absorbing neutrons. Whereas in the case of $\mathrm{X}$ - and gamma-rays, the light elements present in tissue are only slightly absorptive, these same elements (or at any rate, the hydrogen) have properties the very reverse where neutrons are concerned. On the other hand, hydrogen-bearing materials such as water or paraffin, if placed around a neutron source, can be turned to account in slowing down and partially absorbing the neutrons before they reach the personnel. In practice, tanks of water or paraffin $50-100 \mathrm{~cm}$. across are used for screening purposes. About $50 \mathrm{~cm}$. of paraffin reduces the total number of neutrons to about 1 per cent, while a few per cent of boric acid in water reduces the slow neutron activity to about one third of that produced by water alone. Having by such means achieved as much absorption of the neutrons as is practicable, further reliance is then placed, as with $\mathrm{X}$ - and gamma-rays, on remoteness of the personnel from the neutron source.

\section{International MONUMENT to X-RAY AND RADIUM MARTYRS}

What I have tried to set down in this memorial lecture is largely intended for the younger generation who, equipped as they are, like any modern army, with adequate defensive measures, will, I hope, sometimes spare a thought for those X-ray pioneers who, undaunted by long and sometimes unbearable suffering, which drugs might utterly fail to relieve, and which was perhaps followed by mutilating operations or a cruel death, continued to apply themselves indefatigably to perfect the use of Röntgen's discovery for the benefit of humanity. Their martyrdom prepared the way which rendered the present use of X-rays free from danger.

Such matters have a world appeal, though it was in less troubled days that the German Röntgen Society erected in Hamburg a monument to the $\mathrm{X}$-ray and radium martyrs of all nations. The monument, which was unveiled on April 4, 1936, takes the form of a simple rectangular column of sandstone surmounted by a laurel wreath. The names of radiologists, radiographers, physicists, chemists, laboratory workers and nurses whose deaths were due to work with $\mathrm{X}$-rays and radium are engraved on the sides. The total is 169 names spread over fifteen different nations: though it is probable that the list is now by no means complete, nor does it attempt to take cognizance of the large number of less serious casualties. 